\title{
FOLKLORIK BAĞLAMDA ANLATI: GELENEK, DİL VE YORUM
}

\section{Emir İLHAN*}

\section{$\ddot{O} \mathbf{z}$}

$\mathrm{Bu}$ makalede, geçmişe ilişkin deneyimleri bir hikâyeleme biçimi olan anlatının, dil ile nasıl geçmişten miras alınarak bir gelenek hâlini aldığı folklorik bağlamda ele alınmıştır. Bu bağlam, bir dil geleneği içinde geçmişten bugüne bir yorum ile ulaştığ 1 temel alınarak belirlenmiştir. Sözlü kültürden yazılı kültüre geçişle birlikte anlatı, tekrara dayalı "söz" ile sonraki kuşaklara aktarılırken, yazılı kültürle birlikte yoruma dayalı "yazı" ile aktarılmaya başlanmıştır. Bu değişimin en önemli noktası, anlatının "metin" ile aktarılıyor olmasının bir "yorum" sorununu gündeme getirmiş olmasıdır. $\mathrm{Bu}$ da, kuşaklar arasında farklılaşan ama aynı zamanda geleneğinden kopmayan bir dil değişimini beraberinde getirmiştir. Bu değişim karşısında, folklorik anlamda anlatının, metnin doğurduğu yorum ihtiyacının etkisiyle bir form değiştirerek, sözlü kültürdeki ritüelistik çabanın, yazılı kültürle birlikte estetik bir çabaya evrilmesiyle sonuçlanmıştır. Böylece, folklorik bağlamdaki anlatı bir dil geleneği içindeki yorum çeşitliklerine, sözlü kültürdeki anlatı gibi direnmeden kapısını aralamıştır. Sonuç olarak, dilin bir süreklilik içinde oluşturduğu gelenek; anlatıyla, sözlü kültürün biçimsel amaçlarını değiştirerek yazının sunduğu olanaklarla deneyimi tekrar edilebilirlikten yorumlanabilir olmaya dönüştürmüştür. Bu makale bu süreği ortaya koymaya çalışacaktır.

Anahtar Sözcükler: Halkbilim, anlatı, gelenek, dil, sözlü kültür, yazılı kültür ve yorum.

\section{NARRATIVE IN FOLKLORIC CONTEXT: TRADITIN, LANGUAGE AND INTERPRETATION}

\begin{abstract}
In this article, how narrative, which is a form of making past experiences into a story by language with taking heritage from the past, became a tradition will be discussed in folkloric context. In this context, narattive wiil be determined in the that base narrative has reached today with language within a language by interpretation. Narrative was transferred to next generations by "statement" based on repetition with transition to written culture from oral culture, but with written culture it was began to be transferred by "writing" based on interpretation. The most important point of this change is that it has brought the issue of "interpretation" while it was being transferred by "text". This case has also brought change of language between generations which is being differentiating but also never departing from tradition. In response to this change, the ritualistic effort evolvled an aesthetic effort with written culture as a result of change of narrative with the interpretation needs of text in the sens of the folklore. Thus, narratibe in folkloric context has opened the door for diversity of interpretation in oral culture wihtout resistance as told in oral culture. Consequently, tradition which is comprised by constant languge has become is able to be interpretetive while was repeatable with the possibilities presented by writing with changing formal puposes of the oral culture by statement and narrative.
\end{abstract}

Keywords: Folklore, narrative, traditions, language, oral culture, written culture, text and interpretation.

\footnotetext{
* Öğr. Gör.; Akdeniz Üniversitesi, Edebiyat Fak. Türk Dili ve Edebiyatu Bölümü, emirilhan@akdeniz.edu.tr.
} 


\section{Giriș:}

Geçmiş her zaman bir "deneyim" çerçevesinde cazip olan bir olgudur. Ya da geçmişi cazip yapan şey bir önceki neslin deneyimleri olmalıdır. Bu, hem bilimde hem felsefede hem de dinde böyledir. Dahası bunların ötesinde gündelik yaşam içinde "deneyim" her zaman değerli olagelmiş, bu vesileyle bir önceki kuşağın mirası çoğu zaman korunma ve sürdürülme çabasının konusu olmuştur. Bunun daha da ilginç örneğine halk edebiyatında rastlanır. Halk edebiyatındaki anlatmalık türlerde olduğu gibi bir anlatıcı aracılığıyla, önceki kuşakların deneyimleri ya da evren / dünya hakkındaki görüşleri sözlü bir şekilde sonraki kuşaklara aktarılır. Bu anlamda, deneyimi hikâyeleme biçimi olarak anlatı; masal, atasözü, destan, efsane, türkü gibi türleriyle folklorik bir biçim içinde, geçmişteki ataların mirasının bugünün kuşaklarına aktarılmasında en çok kullanılan yoldur. Burada vurgulanan biçim nosyonu, folklorik bağlamın anlatı açısından sözün etkisi altında değerlendirilmesini sağlar. $\mathrm{Bu}$ anlamda dil, söze dayalı olarak belli biçim ya da formlarda geleneğin sonraki kuşaklara aktarılarak devam ettirilmesinin öncüsü olur; ancak dil, geçmişin geçmiş olmasına tutunamayacak kadar dinamik tinsel bir "araç" olduğu için, geleneğin devam etmesinin tarzlarını da değiştirir. Başka bir ifadeyle söze dayalı bir dille miras alınan, gelenek deneyimlerinin ya da dünya görüşlerinin; sözlü kültürün çevreni içindeki sözün olanaklarıyla tekrara ve dolayısıyla taklide dayanan bir aktarılma söz konusuyken, yazılı kültür bu geleneğin devam ettirilmesinin ölçütlerini değiştirmiştir. Bu değişim, sözün dinleme odaklı tekrara dayalı bir anlatıyla geleneği devam ettirmesinin karşısında, yazının okuma odaklı yorumuna doğru bir çizgi izlemiştir. Ong’un "Sözlü iletişim insanlar birleştirir: Yazı ve okuma ise kişinin tek başına yaptığı ve kendi iç dünyasına döndüğü eylemlerdir” (1999: 87) şeklinde ileri sürdüğü gibi, sözün dinlenmesi sırasında anlatıcı ve dinleyici arasında yüz yüze olmanın sağladığı imkânlar, yazıyla birlikte değişmiştir. Dinlemede, söylenen şeyin anlamının, sınırlı zamanda anlaşılmasının tekrara ya da taklide duyduğu ihtiyaç yazıyla birlikte değişmiş, anlam artık daha geniş zamanda üzerinde düşünülerek yoruma dayalı bir anlama olană̆ının konusu olmuştur.

Söz konusu edilen bu dönüşüm, bir dil içinde, daha doğrusu bir dil geleneği içinde gerçekleşmesi nedeniyle, bir kopukluktan ziyade 'süreklilik olarak bir devam'da değerlendirilebilir niteliktedir. $\mathrm{Bu}$ devam olanağını, Bat1 düşüncesinde yorum bilgisi geleneği ortaya koymaya çalışmıştır. Özellikle Gadamer'in dil ve yorum ile ilgili düşünceleri, 'gelenek' kavramı çevresinde şekillenir ( $b k$. Kisiel, 2002 ve Gadamer, 2002). $\mathrm{Bu}$ da, onun "metin" odaklı yorum geleneği düşüncesini, özellikle edebiyatta "estetik" sorunu çerçevesinde önemli hâle getirir. Gadamer'in dili geleneğin konusu, geleneği de dilin 
bir konusu yapması, bir devrim niteliğinde olup, metin temelli anlatı görüşünün savunulması için bir zemin hazırlamıştır.

Edward Shils'ın Gelenek adlı çalışmasındaki "geçmişten günümüze intikal ettirilen ya da miras bırakılan herhangi bir şeydir” (2002: 156) görüşünden hareketle, geleneğin, intikal ettirilen geçmiş düşüncesi çerçevesinde ele alınması olanaklıdır. Aynı zamanda bu düşünce, Gadamer'in dil görüşündeki dilin intikal ettirici yönü ya da gücü bağlamıyla ilişkilendirildiğinde, dil içinde devam eden anlatının söze dayalı tekrarından (bazı anlatılarda temsilinden), yazıyla kurgulanan metindeki yoruma geçiş arasında bir süreklilik vardır. Sözlü kültürden yazılı kültüre geçişte içerik ya da anlam temelinde bir kopukluk yerine, çoğunlukla halk bilimsel çerçeveden bakıldığında, biçim temelindeki bir kopukluktan söz edilebilir ancak bu bir 'kopukluk' değil 'süreklilik' olarak kabul edilir. Bu bir anlamda, yazı temelli metnin köklerinin, söz ve söze dayalı metnin toprağına uzandığı yolunda bir görüştür. $\mathrm{Bu}$ da geleneğin, zaman, mekân, biçim $v b$. gibi formların anlatı temelinde dönüşmesidir ki bu bir anlamda "büyük tevârüs" tanımını hak edecek kadar önemli bir dönüşümdür. Yazının sözden alarak farklılaştırdığı biçim ve biçimin sunduğu olanaklardır. Bu olanaklar, sözlü kültürde deneyimin ya da evren görüşünün tekrara dayalı anlatımına imkân veren belleği güçlendirme çabasıyken, yani unutmaya ya da hataya imkân vermeyen bir ritüelistik çabayken; yazılı kültürde bu olanaklar yazının sağladığı, unutma kaygısını aşan, daha çok 'anlamı çeşitlendirerek anlama'yı derinleştirme imkânını sunar. Başka bir deyişle, okuma sırasındaki yorum ile derinlerine inilerek kazı yapılan bir metin, ritüelistik kaygının ot bitmediği topraklarda estetik çiçeklerinin filizlenmesini sağlar. Çünkü yazı ile yakalanmak istenen, sözlü kültüre ait anlatının içeriğinde, anlamın özgür atlarını koşturma çabasıdır. Yorum derinleştikçe anlam da derinleşecektir. İşte bu, bir anlatıda folklorik bağlamda bir "kopukluk" değil, bir farklılaşmaya dayanan, dilin köklerinden beslenen dönüşümün, estetiğin hayat ağacıdır; bu mitik düşüncenin çeşitlemelerle yaşatılmasıdır.

Buradan hareketle anlatının, folklorik bağlamdaki bu dönüşümünün izleri gelenek, dil, yorum ve metin kavramlarından hareketle sürülecektir.

\section{Anlatının Folklorik Penceresi:}

Bir hikâyeleme biçimi olarak anlat1, ilksel hâliyle sözlü kültür evresinde görece eski kuşağın deneyimlerini ya da evren hakkındaki görüşlerini / inançlarını kendilerinden sonraki kuşağa aktarmak için kullandıkları bir edebî türdür. İlk hâliyle mitos ya da söylenceye dayanan anlatı türleri (başta masal, destan, efsane gibi türlerden oluşan anlatı), cetlerin torunlarına kendi algı, inanç ve sağduyu bilgilerini aktardığı bir geleneğin taşıyıcısı görevini üstlenmiştir. Tabii ki, sözlü kültür evresinin neredeyse hem edebî ruhunu yansıtan bir 
gelenek aktarma biçimi olan anlatı, aynı zamanda bir tarih yazımı biçimi olarak da "antik dönem" ya da "antikite" denilen çağın düşünce ve eylem evreni hakkında bilgi sahibi olduğumuz bir etkinlik olarak hâlâ önemini korumaktadır. Aslında bu önemi daha da perçinleyen, yazılı kültür evresinin enformasyon çağında artan bireyselleşmenin bunalımlarıdır. Bir "hikâye" olarak anlatı, tarihsel olan ve çoğunlukla deneyimlerin kuşaktan kuşağa aktarıldığı, söze dayalı edebî bir tür olarak kabul edilirse yazılı kültür dönemi söz konusu olduğunda, bu kabulün geçerli olup olmadığı şüpheli olacaktır. Bu şüphe bir bakıma, sözlü kültürden yazılı kültüre geçiş dönemlerinde anlatının geçirdiği dönüşümü ve bireyselliğin yarattığı sorunları da farklı bir bakış açısından ya da bağlamdan ele alma ihtiyacını arttırmaktadır.

Sözlü kültür evresindeki anlatının biçimi ve türleriyle, yazılı kültür çağındaki anlatıların biçimi ve türleri arasındaki çatışma, kopukluk, bakılan pencereye göre farklı değerlendirilebilir. Bir açıdan, yazılı kültürün anlatı türleri 'sözlü kültürün anlatısından bir kopmayı sağlamıştır’ denilebileceği gibi diğer bir pencereden bunun bir kopma değil olsa olsa 'bir çatışmayı içeren bir süreklilik olarak görülmelidir' görüşü savunulabilir. İşte bu ikinci bakış açısı bu yazıda 'folklorik bağlam' denilen hareket noktasıdır.

Sözlü kültürden yazılı kültüre geçişte anlatının geçirdiği dönüşümün ve bu dönüşümün neden olduğu sorunların, folklorik bakış açısından ele alınabilecek ipuçlarını Walter Benjamin verir. Benjamin, "hikâye anlatıcısının hayatımızda hiçbir hükmü" kalmadığı ya da "anlatıcılık sanatının sona erdiği” yönündeki modernlik eleştirisinde, "Deneyim değer kaybetti” diyerek bir tespit yapar. Modern dönemde artık "bir şeyi layıkıyla hikâye edebilen insanlara gittikçe daha az rastlıyoruz" diyen Benjamin (Benjamin, 2012: 77), bunun yazılı kültürle maruf olan modern dönemlerde hikâye anlatıcılarına bu kadar az rastlanmasının nedenini, "enformasyon ağının belirleyici rolü” olarak görür (Benjamin, 2012: 82). Çünkü hikâye anlatıcılarının beslendiği kaynağı, "ağızdan ağza aktarılan deneyim" olarak gören Benjamin'in buradaki dikkate değer tespiti, hikâye anlatıcısının söze dayalı bir anlatıyla geçmişteki deneyimlerini hikâye etmesidir yani bir 'deneyim', 'söz'le aktarılan bir 'anlatı' olarak hikâyeleşir.

Buradaki deneyime yapılan vurgu, deneyimlerin kuşaktan kuşağa aktarılışının bir 'tekrar' nosyonuna vurgu yaparak, geleneğin intikalinin bir temasını ortaya koyar. Benjamin'in anlatı ile deneyim arasında kurduğu ilişki, bir önceki kuşağın temsilcilerinin geçmişteki deneyimlerinin 'söz' ile aktarılarak bir 'gelenek' oluşması anlamına gelmektedir. $\mathrm{Bu}$ durumda, anlatının folklorik bağlamdaki bu çerçevesinin daha netleşmesi için, anlatının gelenek ve dil kavramları açısından köklerini irdelemek yararlı olacaktır. 


\section{Gelenek ve Dil:}

Modern anlamıyla İngilizcede gelenek anlamına gelen tradition kelimesi, İngilizceye XIV. yüzyılda eski Fransızcadaki tradicon kökünden gelmiştir. O da, Latince tradere'den vermek, teslime etmek - anlamına gelen kök sözcükten türeyen Latince traditionem'den gelmiştir. Günümüzdeki kullanımına en yakın şekliyle XVII. yüzyılda geçmişe saygıyı ifade eden bir kullanımı da içerecek şekilde babadan oğula aktarılan şeyler için kullanılan genel bir sözcük haline gelmiştir. Bu kullanımda traditionun İngilizcede genel bir aktarma sürecinde sayg1 ve görev anlamına ilişkin bir vurgu yapılmaya başlamıştır (Williams, 2007: 386-7). Görüldüğü gibi geleneğin birçok anlam dönüşümüne uğramasıyla birlikte traditum, geçmişten günümüze intikal ettirilen ya da miras bırakılan herhangi bir şey anlamına gelir. İnsan düşüncesinin, hayal gücünün, eyleminin ürünü olan her türlü maddi ve manevi mirasin aktarılmasıyla oluşan gelenek, nesneler, pratikler, kurumlar, kuramlar ve tasarılar tarafından oluşur. Bu anlamda, inançlar, binalar, abideler, resimler, kitaplar, araçlar, folklorik öğeler $v b$. gibi doğal nesneler dışındaki insan yaratıları geleneğe aittir ve geçmişten tevarüs edilirler.

Diğer bir deyişle, onlar için gelenek, onlar için geçmişte olmuş olan ve geçmişten tevarüs edilmiş veya intikal ettirilmiş olan 'traditum'dur. Örneğin, İngilizceye yapılan en son tercümesiyle İlyada, bir 'traditum'dur; yani bir gelenektir. Kısaca, gelenek, şimdideki geçmiştir (Shils, 2002: 156-7). İntikal ettirilen geçmiş olarak gelenek, geçmişi geçmişte kalan bir maziden kurtararak yeniden zamansallaştırır; ancak bu intikal süreci, ya da kuşaklar arası tevarüs silsilesi boyunca çağın değişimleri de etkili olur. Geleneğin bir sonraki kuşağa intikali için iki önemli unsuru vardır: temsilciler ve değişimler. Öncelikle bir gelenek kuşaklar boyu temsilciler tarafından intikal ettirilir; ikinci olarak gelenek bu intikal sırasında aynı kalamaz, değişir; ancak bu değişim, köklü olabileceği gibi küçük de olabilir.

Geleneğin intikal ettirilebilir olması, tabiatıyla 'aynı şeyin olduğu gibi nakli' demek değildir. Değişmeden intikal ettirilen gelenek neredeyse yok denecek kadar azdır. Hatta teorik olarak imkânsızdır. Çünkü en azından iki kuşak arasında geçen zaman içinde, bir duyuş, düşünüş ve algılayış biçimine etki eden, onu değiştiren etkenler mevcuttur. Bu nedenle, gelenek değişmez değildir. Bu noktaya folklorun mahiyetindeki 'çeşitlenme özelliği' çerçevesinden de bakılabilir (Yıldırım, 1998: 69). Shils'ın da dediği gibi, gelenek içinde kabul edilen şeyler, intikal süreleri boyunca değişikliğe uğrarlar. Örneğin bir metin, fiziksel olarak aynı şekilde intikal etse dahi alıcılarının yorumu ile değiştirilir. Aynı şekilde resim, heykel, müzik $v b$. gibi sanat eserleri için de geçerlidir. Bununla beraber fikirler, kuramlar da intikal edildiği kuşaklar serisi boyunca, özüne bağlı olarak bir çeşitlemeler şeklinde değişikliğe uğratılır. Bir gelenek 'zamana dayalı bir zincir' olarak benimsenerek, intikal ettirilen yönleri değişime uğramalarına 
rağmen değişen unsurları temel unsurlarıyla bağlantılı olmaya devam eden bir görüntüye sahip olurlar; yani intikal edilen kuşaklar, intikal ettirilen bir geleneği, bir zincir serisi içerisinde değişmesiyle birlikte özüne bağlı olarak kabul ederler (Shils, 2002: 158).

Bir gelenek ancak intikal ettirildiğinde yaşar. Tabii ki, bu da bir temsiliyetin istenciyle yapılabilecek bir şeydir; yani bir gelenek, istekli bir insan ya da insan grubunun bir sonraki kuşağa intikal ettirmesi, o kuşağın bunu alarak yeniden inşa etmesi ve devam ettirmesiyle yaşar. Bir gelenek, temsiliyetini üstlenen kişiler olmazsa, kendi başına yok olup gider (Shils, 2002: 159).

Bir şey modadan farklı olarak, eğer en az üç kuşak boyunca bir zincir hâlinde intikal ettiriliyorsa bu gelenektir. Burada, geleneğin modadan farkını ortaya koyabilecek bir ipucu vardır: geleneğin özü. Geleneğin özü, onun intikal ettirilebilirliğini sağlar; yani alıcı kuşağın benimsemesini mümkün kılan bir özdür. Bu anlamda 'gelenek' herhangi bir özsel içerikle ilgili bir intikalin konusudur. Bir özün intikali olarak gelenek, değişen bir biçimden diğerine, bir 'gelenek zinciri' hâlinde çok uzun bir süreler boyunca varlığını sürdürür (Shils, 2002: 160-161). Burada dikkate değer olan nokta, geleneğin intikal ettirilebilirliğini sağlayan bir öze sahip olması ve bu özün de bir biçim değişimi yoluyla bir zincir gibi gelecek kuşaklara bağlanmasıdır. Geleneğin intikal etmesi, değişerek sonraki kuşaklar tarafından benimsenmesi, son kuşağın içinde yaşadığı zamanın neden olduğu yenilik tarafından ele geçirilir. İntikal etme, aynı zamanda bir yeniliğin de konusudur.

Bir gelenek için yenilik kavramı, bir yorum konusudur yani geçmişte var olmuş hâliyle bir anlamı olan bütünlüklü bir nesnenin intikali, ancak bir yorum çerçevesinde gerçekleşir. İşte 'yenilik', bir 'yorum' bağlamında intikali sürdürülebilir yapar. Gadamer'in ufuk açıcı çözümlemesiyle bir yorum, "içinde gerçekleştiği tarihsel durum” aracılığıyla şekillendirilir. Ona göre, "biz bir geleneği bir gelenekten hareketle yorumlarız. Gelenek yoruma temel sağlar ve yeni yoruma davetiye çıkarır; bu tazelenen yorum geleneği canlı tutar. Yorum hareketini intikal ettirme hareketi canlandırır"(Gadamer akt. Kisiel, 2002: 183). Gadamer'e göre, bir yorumla gerçekleştirilecek anlama, geçmişin intikal eden mirasının içselleştirilmesiyle; bir öznenin salt kendi eylemiyle değil, geçmiş ile şimdi arasındaki bir geçişin intikal etmesiyle mümkün olur. Gadamer, Heidegger' in 'dünyaya atılmışlık' kavramından hareketle, bir öznenin bir geleneğe ait olmasıyla mümkün olan 'anlama' eylemini, içinde doğulan bir gelenek tarafından şekillendirildiğinin altını çizer. Bir gelenek tarafından devraldığımız bu 'anlama' nosyonuyla biz kendimize ait olmaktan çok daha fazla tarihe ait oluruz. Böylece, kendimizi "yaşadığımız ailede, toplumda ve devlet içinde anlarız" (Kisiel, 2002: 185). Böyle bir anlama, insanın içinde yaşadığı şimdinin, geçmişin bir süreği olduğunu ortaya koyar. Eğer geçmiş ile şimdi, bir 
'anlama' nosyonu ile birleşiyorsa, bu birleştirici güç nedir? Bu güç dildir, dilin geleneğidir ki geleneğin intikali de dil ile yapılır: bu intikal, "dil 'geleneği' vasıtasıyla biz cetlerimizle ortak bir anlam boyutu içinde hareket ederiz"(Kisiel, 2002: 186). Buradan hareketle böyle bir anlam boyutu içinde yorumu mümkün kılan şey, dilin hakkında konuşulan şeyle ilişkili olma, bir dilsel geleneğin içinde ve onun aracılık ettiği anlam alanında hareket etmektir.

Eğer bir gelenek, bir yorum bağlamında yeniden şimdiki zamanda inşa ediliyor ya da yeniden zamansallaştırılıyorsa, bu intikal eden geleneğin konusu ancak metin olmalıdır; yalnız bir metindir yorum konusu olabilecek. Çünkü bir yorum, ancak bir anlama ilişkin bir yorumdur. $\mathrm{Bu}$ da kuşaklar arası zaman farkının gücüyle değişime uğrayan bir yorumdur. Demek odur ki, intikal eden bir metin olarak gelenek, bir dil içinde, dil ile intikal eder.

\section{Metin ve Anlatının Tekrardan Yoruma Dönüşümü:}

Dilde, ifadenin sözlü biçiminden yazılı biçimine bir geçiş olarak metin, Gadamer'in ele aldığ ş̧ekliyle bir dil geleneği içinde yorumlanarak geçmişle şimdinin ufukların kaynaşmasını sağlar. Metin ile birlikte anlatının sözden yazıya dönüşümü, edebî anlayışlarda da köklü bir farklılaşmaya yol açtı. Bunun en açık örneği, bir sözlü kültür dönemi anlatısı olan destan ile roman arasındaki farktır ya da daha doğru bir deyişle destandan romana doğru bir farklılaşmadır. Destan, bir anlatıcının karşısında bir dinleyiciye ya da dinleyici topluluğuna söylenen bir anlatı türü olarak, söyleyici ile dinleyiciyi karşı karşıya getirirken; bunun aksine roman, yazarından uzakta, bir metin olarak okuyucunun karşından açılan binlerce kapılı bir saray gibi dikilir. Burada Benjamin'in ifade ettiği gibi, bir destan anlatıcısı "hikâyesini deneyimden çekip alır, kendi deneyiminden ya da ona aktarılandan ve o da bunu kendisini dinleyenlerin deneyimi hâline getirir." Yani, sözlü anlatıda, anlatıcı ile dinleyici arasında bir "deneyim" odaklı bir söyleme-dinleme ilişkisi varken, romanla birlikte yazar ile okur arasında bir kopukluk olmuştur. "Romancı ise kendini tecrit etmiştir" (Benjamin, 2012: 81). Bir yazılı kültür ürünü olan roman, destan gibi deneyimlerin paylaşıldığı bir ortam olmak yerine bireyin kendi başına metnin içinde anlamın çeşitliliğine kendisini bırakmasını sağlamıştır. Benjamin'e göre roman akıl almaz ya da vermezken, sözlü kültür anlatısı olan destan gibi türler bir nevi "bilgelik" olarak kabul edilecek akıl verme amacını güder. Ona göre, sözlü anlatı biçiminin amacı yazılı anlatı türü olan romanla birlikte değişmiştir: "Hikâye dinleyen kişi, hikâye anlatıcısının misafiridir; hikâye okuru bile bu mecliste yerini alır. Roman okuru ise, okurların en yalnızıdır... Onu kendisine mal etmek, adeta yutarcasına okumak ister"(Benjamin, 2012: 92). Bu da okurun, metinle baş başa kaldığı durumda, metni anlama çabasında bir 'yorum' faaliyetine başvurması demektir. 
Her ne kadar sözlü anlatı türlerinden farklı olarak roman, okuyucuyu tecrit ederek metne 'hapsetme' gibi bir durumla karşı karşıya getiriyorsa da, okuyucunun metni anlama çabası sırasındaki ‘yorum' faaliyetini mümkün kılan bir 'dil geleneği' vardır. Bu gelenek, okuyucunun metni yoruma dayalı olarak anlamasını sağlar. Yoruma dayalı anlama, bir dinleyicinin sözün söylediği bağlama odaklanması gibi değil, bir okuyucunun metin içindeki anlam ilişkilerini kuran dil geleneğine bağlı olarak gerçekleşir. Bir kelimenin anlamı, sözlü kültürde çoğunlukla bağlamdan hareketle anlaşılırken, yazılı kültürdeyse dilin kendisinde anlaşılır (Olson akt. Ong, 1999: 128). Bu da anlamanın yoruma bağlı olarak kişiden kişiye değişmesi demektir; ancak okuyucuya bırakılan 'yorum', bir geleneğin intikal ettirildiği dil içindeki anlamların çeşidini de sunar. Metin, farklı anlamlara açık olduğu sürece bir yorum konusu olur. Yorum konusu olurken de kendi tekrarlama pratiklerini de özendirebileceğini unutmamak gerekir (Goody, 2013: 117).

Dil, bir gelenek için varlık koşulu olduğu kadar, gelenek de dilin varlık koşuludur. Gadamer'e göre, bir gelenek içinde gerçekleşen insanî anlama, dil içinde/dil vasıtasıyla bir anlamadır. Geleneğin, daha da önemlisi bir dil geleneğinin içinde ancak bir yorum yapılarak anlama gerçekleşir. Bu geleneğin dilsel vuku buluşudur; insana anlama olanağını veren şeydir bir dil geleneği içinde olmak (Kisiel, 2002: 182). Bu durumda, bir anlam, bir metin karşısında bir yorum ile ele geçirilir. Geleneğin intikal ettirildiği; bir dil içinde intikal ettirildiği bir anlam deposu olan metin, bir yoruma açık olduğunda intikal ettirilmiş olur ancak.

Romanın tecrit edici bireyselleştirici doğasından kaynaklanan, bir destan türünün biçiminden bir 'kopuş' olarak anlaşılabilecek örnekten farklı olarak, yine bir yazılı kültür ürünü olan hikâye örneği vardır. Benjamin'in verdiği diğer bir örneğe göre, anlatma sanatıyla Leskov Aldatma ve Beyaz Kartal adlı hikâyelerinde farklı bir olanağı gösterir. Bu olanak, romandan farklı olarak, tıpkı sözlü kültürdeki anlatısının destanındaki gibi, hikâyede hiçbir açıklama yapmadan, olağanüstü ve mucizevî konuları ayrıntılarıyla anlatır; ancak okuyucuyu hiçbir psikolojik çözümlemeye zorlamaz; sadece okuyucunun olayları kendi anladığı biçimiyle yorumlamasına izin verir (Benjamin, 2012: 82). Bu örnek, bir yazılı edebî tür olarak anlatının hikâyeleme biçimi olarak, yine yazının olanaklarına başvurduğu, ancak hiçbir şekilde roman gibi salt bireyselleştirici bir farklılaştırmayı yapmadığı anlamına gelir ki bu da, yazılı bir anlatının bir geleneğin intikalinden hareketle sözlü kültürün köklerine bağlanılabileceğini gösterir. Hikâye, Benjamin'in de söylediği gibi: "Kendini tüketmez, gücünü toplar ve korur, y1llarca sonra bile harekete geçirilebilir” (Benjamin, 2012: 83).

Hikâyenin gücü, köken olarak bir anlatı biçimi olarak destana dayanır. Sözlü kültür evresindeki hikâye anlatıcılığı geleneğinin sonraki kuşaklara intikali, 'tekrar' ile 
gerçekleşmişti. Daha yazının olmadığı dönemlerde anlatı tekrara dayanmasaydı, hikâyeler ya da anlatı sanatı yok olup giderdi. Çünkü hikâyeler dinlenirken onları eğirip dokuyan birileri yoktur artık. Dinleyici hikâyeyi dinlerken kendini ne kadar unutursa, dinledikleri hafızasında o kadar yer eder. Kendini anlatının ritmine kaptırdığında hikâyeleri öyle can kulağıyla dinler ki, kendini hiç zorlamadan onları yeniden anlatırken buluverir. Hikâye anlatma yeteneğine beşiklik eden ağ işte böyle örülmüştür (Benjamin, 2012: 84).

Buradan hareketle Benjamin, dinleyiciler ile hikâye anlatıcısı arasında kurulan bu ilişkiyi 'akılda tutma' ya da 'hafıza' sorunu olarak değerlendirir. Ona göre hafıza, destansı bir melekedir; hafızayla destan olaylarının akışını sürdürerek, kuşakların bunu sahiplenmesini sağlamıştır. Eski Yunan'da destan sanatının esin perisi olan Mnemosyne yani Hatırlayan Tanrıça, hatıranın kayıtlarını tutan destansı bir varlıktır. İşte bu Esin Perisi destandan romana değin bu gücünü korumuş, yüzyılların birikimi içinde roman, destanın bağrından yavaş yavaş çıkmıştır. Her ne kadar bu Esin Perisi, hatırayı destanda farklı, hikâyede farklı, romanda farklı bir biçimde ortaya koymuş olsa da, destan, hem hikâyenin hem de romanın ortak paydasıdır. Ve bu ortak payda, "bir olayı kuşaktan kuşağa aktaran gelenek zinciri” olan "hatıra" anlamına gelen Erinnerung'dur (Benjamin, 2012: 89-90).

İşte bu hafıza ve hatıllama nosyonları, anlatının tekrara dayalı olarak kuşaktan kuşağa aktarılmasını sağlar; ancak bu tekrarın gücü sözlü kültürde etkinken, yazılı kültürdeki (geleneğin oluşturduğu mirastan hareketle oluşturulan) metin odaklı anlatılar, 'yorum' ile hatırlamanın konusu olmuş ve böylece sonraki kuşaklara aktarılmaya başlamıştır.

Bir başka açıdan söylenirse, söz ile gerçekleşen anlatı aynı zamanda geçmişin deneyimler çerçevesinde şimdide yeniden hatırlanmasına dayanır. Connerton'a göre anlatı, anlatılan bir öyküden öte, oyun biçiminde canlandırılan bir kült'tür. Öyküsü, geçmiş olayları anlatan geçmiş zamanın diliyle değil, metafizik şimdiki zaman diliyle anlatılır. Bir anlatı çerçevesinde, kutsal bir olayın 'yeniden canlandırıldı̆̆ı' ya da 'temsil edildiği' söylenebilir. Böyle anlatıların performanslarının gerçekleştiği törenlere, katılımcıları tarafından bir 'biçim' verilir. "Kült törenlerinde rol alanlar, mitos olayın sözde görgü tanıkları durumuna geldiklerinde, mitosun yüceltilmiş gerçekliği, her yıl yeniden sahnelemiş olur.” (Connerton, 1999: 69). Bu 'tanıklık' kavramı geçmişin gelenek olabilmesi açısından önemlidir. Daha doğrusu geçmişin bir 'bellek' içeriği olarak hatırlanması ve buradan hareketle tekrara dayalı bir performans olarak anlatının oluşturduğu ritüelistik temsil, Benjamin'in destansı hafiza (Gedachtnis) dediği esin gücüne dayanır (Benjamin, 2012: 90). Bu destansı hafiza, örneğin Homeros'un destanlarındaki, hikâye anlatıcısının birçok olaya adanmış anlatısı, yazılı kültürdeki romanın Esin Perisi'nden beslenen hatırlama (Eingedenken) ile tek bir kahramana, 
tek bir serüvene, tek bir olaya dayanır (Benjamin, 2012: 90).

Sözlü anlatının, geçmişin deneyimlerini şimdiye intikal ettirme çabasındaki dilselliğin ritüelistik yapısı, aynı formda, aynı biçimde ve aynı anlamı koruyacak şekilde tekrara dayanırken, yazılı anlatı, anlama ilişkin yorumlarla yeniden anlam kazanır. Diğer bir deyişle, edebî metinler her dile getirildiklerinde ya da her okunduklarında, yalnızca bir kez değil ama her seferinde metin bütünlüğünün çerçevesini ifade eden anlam ve ses ilişkileri ortaya çıkarır. Metin, yeniden okunduğunda yeni anlam boyutları keşfedilir (Gadamer, 2002: 315).

\section{Sonuç:}

Sonuç olarak, sözlü kültürdeki anlatı biçiminden yazılı kültürün anlatı biçimine ya da bir metin olarak sözün tekrarından yine bir metin olarak yazının yorumlanmasına geçiş, dil vasıtasıyla intikal ettirilen geleneğin içinde vuku bulur. Bu iki tür de, aynı gelenek zincirinin tinsel özü ile şekillenir. Kısaca, sözün tekrarına dayalı oluşturulan biçimsel yapının ritüelistik performansıyla güçlenen hafıza, güvenilir hatıralarla geleneği; yazının sabitleştirdiği simgelerin karşılık geldiği anlamın yeni ufuklarına açılmasını sağlayan hafızanın imgelemle işbirliğiyle oluşan estetik çabayla yeniden yorumlanabilecek hatıralarla geleneği intikal ettirir.

\section{Kaynaklar:}

BENJAMIN, W. (2012). Hikâye Anlatıcısı, Son Bakışta Aşk. N. Gürbilek (drl. ve çev.). 6. Baskı. İstanbul: Metis Yayınları,77-100.

CONNERTON, P. (1999). Toplumlar Nasıl Anımsar. A. Şenel (çev.). İstanbul: Ayrıntı Yayınları.

GADAMER, H. G. (2002). Metin ve Yorum, Hermenutik ve Hümaniter Disiplinler. H.Arslan (drl. ve çev.). İstanbul: Paradigma Yayınları, 284-319.

GOODY, J. (2013). Yazılı ve Sözel Arasındaki Etkileşim - Okur Yazarlık Aile Kültür ve Devlet Üzerine İncelemeler. O. Bulut (çev.). İstanbul: Pinhan Yayıncılık.

KISIEL, T. (2002). Geleneğin Vukubulması: Gadamer ve Heidegger'in Hermeneutiği, İnsan Bilimlerine Prologomena. H. Arslan (drl. ve çev.). İstanbul: Paradigma Yayıncılık, 181204.

ONG, W. J. (1999). Sözlü ve Yazılı Kültür - Sözün Teknolojileşmesi. S. P. Banon (çev.). 2. Bask1 İstanbul: Metis Yayınları.

SHILS, E.(2002) Gelenek. Insan Bilimlerine Prologomena. H. Arslan (drl. ve çev.). İstanbul: Paradigma Yayıncilık, 145-180.

WILLIAMS, R. (2007). Anahtar Sözcükler - Kültür ve Toplumun Sözvarlı̆̆ı. (3. Baskı). S. Kılıç (çev.). İstanbul: İletişim Yayınları.

YILDIRIM, D. (1998). Türk Folklor Araştırmalarının Problemleri. Türk Bitiği. Ankara: Akçağ Yayınlar1, 65-75. 